\title{
Does Leg Length Discrepancy Affect Flexor And Extensor Muscle Strength of the Knee? A Case Series of Paralympic Swimming Athletes
}

\section{Bacak Uzunluk Farkı Diz Ekstansör ve Fleksör Kas Kuvvetini Etkiler mi? Paralimpik Yüzücülere Ait Olgu Serisi}

\author{
Tuğba Kocahan ${ }^{1}$, Bihter Akınoğlu² \\ ${ }^{1}$ Ministery of Youth and Sports, General Directorate of Sports, Directorate of Health Affairs, Eryaman, Ankara, Turkey \\ ${ }^{2}$ Ankara Yildirum Beyazıt University Faculty of Health Sciences, Department of Physiotherapy and Rehabilitation, \\ Ankara, Turkey
}

T. Kocahan

0000-0002-0567-857X

B. Akınoğlu

0000-0002-8214-7895

Geliş Tarihi / Date Received: 14.09.2017

Kabul Tarihi / Date Accepted: 24.10.2017

Yayın Tarihi / Date Published: 02.03.2018

Yazışma Adresi /

Corresponding Author:

Bihter Akınoğlu

Ankara Yıldırım Beyazıt

Üniversitesi, Sağlık Bilimleri

Fakültesi, Fizyoterapi ve

Rehabilitasyon Bölümü,

Ankara, Turkey.

E-mail: rgkardelen@yahoo.com

(C)2018 Türkiye Spor Hekimleri Derneği. Tüm hakları saklıdır.

\section{ABSTRACT}

The aim of this study was to determine the relationship between leg length and muscle strength in three Paralympic swimming athletes with leg length discrepancy, who have no upper extremities below the shoulders in both sides.

Key Words: Congenital abnormalities, lower extremity, muscle strength, swimming

\section{Öz}

Bu çalışmanın amacı konjenital olarak her iki üst ekstremitesi omuz seviyesinden itibaren bulunmayan ve alt ekstremiteleri arasında uzunluk farkı olan üç paralimpik yüzme sporcusunda bacak boyu ile kas kuvveti arasındaki ilişkiyi ortaya koymaktır.

Anahtar Sözcükler: Konjenital anomaliler, alt ekstremite, kas kuvveti, yüzme

Available at: http://journalofsportsmedicine.org and

http://dx.doi.org/10.5152/tjsm.2018.089

Cite this article as: Kocahan T, Akinoglu B. Does leg length discrepancy affect flexor and extensor muscle strength of the knee? A case series of paralympic swimming athletes Turk J Sports Med. 2018;53:47-50.

\section{GÍRIS}

Konjenital ekstremite eksiklikleri, ekstremite kemiklerinin formasyonundaki yetersizlikten kaynaklanmaktadır. Konjenital ekstremite yokluğu hem bireysel, hem de sosyal problemlere yol açar $(1,2)$. Engelli bireylerin spor yapmaları ve kendi kategorilerindeki müsabakalara katılmaları, kendine güven ve arkadaşlık duygularını geliştirerek günlük yaşamda daha aktif ve daha sosyal olmalarını sağlamaktadır $(1,2)$. Konjenital ekstremite anomalisi yirmi bin doğumda bir görülmektedir $(1,3)$. Üst ekstremite konjenital eksikliği ile birlikte alt ekstremitelerde boy farkı da görülebilmektedir. Üst ekstremite konjenital eksikliği ve alt ekstremitelerde boy farkı olması durumunda paralimpik yüzme sporu en ideal spor branşlarından biridir. 
Tıpkı sağlıklı sporcularda olduğu gibi paralimpik sporcularda da kas kuvveti sportif performansin en önemli parametrelerindendir. Literatürde sağlıklı bireylerde yapılan çalışmalarda, alt ekstremite kas kuvvetinin kas hacmi ve bireyin boyu ile ilişkisini gösteren çalışmalar $(4,5)$ olmasına rağmen, Paralimpik sporcularda ekstremite uzunluğu ya da eşitsizliği ile kas kuvveti arasındaki ilişkiyi araştıran herhangi bir çalışmaya rastlanmadı.

\section{OLGULARIN SUNUMU}

Çalışmaya alınan birinci olgu; 22 yaşında erkek idi. Boyu $1.61 \mathrm{~m}$, vücut ağırlı̆̆ $46 \mathrm{~kg}$, spor yaşı 17 yll idi. Sol alt ekstremitesi sağ tarafa göre $9 \mathrm{~cm}$ kısa idi.

İkinci olgu 14 yaşında kadın idi. Boyu $1.58 \mathrm{~m}$, vücut ağırlığı $53 \mathrm{~kg}$, spor yaşı 5 yıl idi. Sağ alt ekstremitesi sol tarafa göre $5 \mathrm{~cm}$ kısa idi.

Üçüncü olgu da 14 yaşında kadın idi. Boyu 1.43 m, vücut ağırlığ $48 \mathrm{~kg}$, spor yaşı 7 yıl idi. Sol alt ekstremitesi sağ tarafa göre $2 \mathrm{~cm}$ kısa idi.

Çalışmaya alınan her üç olgunun da her iki üst ekstremitesi omuz seviyesinden itibaren konjenital olarak yoktu.
Çalışmada incelenen sporcuların diz eklemi kas kuvveti izokinetik cihazla değerlendirildi. Bireylerden değerlendirme öncesinde isınma amaçlı 10-15 dk yürümeleri istendi. Çalışmada bireylerin kas kuvvet ölçümü ISOMED $200{ }^{\circledR}$ (D \& R Ferstl GmbH, Hemau, Germany) izokinetik cihazı ile yapıldı. Çalışma alt ekstremitede diz eklemi fleksör ve ekstansör kas grupları üzerinde, her bir alt ekstremite için ayrı ayrı antropometrik değerler girilerek gerçekleştirildi. Sporcuların üst ekstremiteleri olmadığ tutacaklardan destek alamadıkları için, ek bir kemerle gövde, pelvis ve kalça eklemi stabilize edildi (6).

Değerlendirmede $0-90^{\circ}$ açıları arası konsantrikkonsantrik ölçüm yapıldı. Değerlendirme protokolünde $60^{\circ} / \mathrm{s}$ açısal hızda üç tekrarlı fleksiyon/ekstansiyon hareketi submaksimal olarak yaptırılarak bireylerin ısınması ve hareketi anlaması sağlandı. Isınma hareketinden sonra 30 saniyelik dinlenmenin ardından $60^{\circ} / \mathrm{s}$ açısal hızda beş tekrarlı maksimal fleksiyon/ ekstansiyon hareketi yaptırıldı ve yine 30 saniye dinlenme verildi. Daha sonra $180^{\circ} / \mathrm{s}$ açısal hızda üç tekrarlı fleksiyon/ekstansiyon hareketi submaksimal yaptırılarak yeni hareket hızını anlaması sağlandı.

Tablo 1. Olguların diz fleksiyon ve ekstansiyon zirve tork (ZT) değerleri, agonist/antagonist kas kuvvet oranları ve dominant ve nondominat taraf izokinetik kas kuvvet farkı

\begin{tabular}{|c|c|c|c|c|c|c|c|c|}
\hline & $\begin{array}{l}\text { Kisalık } \\
\text { farkı }\end{array}$ & İzokine & ik kas kuvveti & $\begin{array}{c}\text { D taraf } \\
(\mathrm{Nm})\end{array}$ & $\begin{array}{l}\text { Flek/Eks } \\
\text { oranı (\%) }\end{array}$ & $\begin{array}{l}\text { NDM ta- } \\
\operatorname{raf}(\mathrm{Nm})\end{array}$ & $\begin{array}{l}\text { Flek/Eks } \\
\text { oranı(\%) }\end{array}$ & $\begin{array}{c}\text { D/NDM } \\
(\%)\end{array}$ \\
\hline \multirow{4}{*}{ 1.0lgu } & \multirow{4}{*}{$\begin{array}{l}\text { NDM-9 } \\
\text { cm kisa }\end{array}$} & \multirow{2}{*}{$60^{\circ} / \mathrm{sn}$} & Diz Ekstansiyonu & 171.9 & \multirow{2}{*}{60.3} & 99.1 & \multirow{2}{*}{63.7} & 173.4 \\
\hline & & & Diz Fleksiyonu & 103.6 & & 63.1 & & 164.1 \\
\hline & & \multirow{2}{*}{$180^{\circ} / \mathrm{sn}$} & Diz Ekstansiyonu & 110.4 & \multirow{2}{*}{71.9} & 73.3 & \multirow{2}{*}{73.8} & 150.6 \\
\hline & & & Diz Fleksiyonu & 79.3 & & 54.1 & & 146.5 \\
\hline \multirow{4}{*}{ 2.0lgu } & \multirow{4}{*}{$\begin{array}{l}\text { NDM-5 } \\
\text { cm kisa }\end{array}$} & \multirow{2}{*}{$60^{\circ} / \mathrm{sn}$} & Diz Ekstansiyonu & 98.4 & \multirow{2}{*}{70.3} & 66.1 & \multirow{2}{*}{97.3} & 148.8 \\
\hline & & & Diz Fleksiyonu & 69.1 & & 64.3 & & 107.4 \\
\hline & & \multirow{2}{*}{$180^{\circ} / \mathrm{sn}$} & Diz Ekstansiyonu & 79.3 & \multirow{2}{*}{78.1} & 57 & \multirow{2}{*}{98.9} & 139.1 \\
\hline & & & Diz Fleksiyonu & 61.9 & & 56.4 & & 109.7 \\
\hline \multirow{4}{*}{ 3.0lgu } & \multirow{4}{*}{$\begin{array}{l}\text { NDM-2 } \\
\text { cm kisa }\end{array}$} & \multirow{2}{*}{$60^{\circ} / \mathrm{sn}$} & Diz Ekstansiyonu & 65.8 & \multirow{2}{*}{48.1} & 77.4 & \multirow{2}{*}{37.6} & 85 \\
\hline & & & Diz Fleksiyonu & 31.6 & & 29.1 & & 108.5 \\
\hline & & \multirow{2}{*}{$180^{\circ} / \mathrm{sn}$} & Diz Ekstansiyonu & 48.1 & \multirow{2}{*}{56.4} & 51.6 & \multirow{2}{*}{56.4} & 93.2 \\
\hline & & & Diz Fleksiyonu & 27.1 & & 29.1 & & 93.1 \\
\hline
\end{tabular}

D: Dominant, NDM: Non-dominant 
Ardından 30 saniyelik bir dinleme arası verildi ve $180^{\circ} / \mathrm{s}$ açısal hızda 15 tekrarlı maksimal fleksiyon/ekstansiyon hareketi gerçekleştirilip test tamamlandı. Değerlendirmeler bilateral olarak gerçekleştirildi. Hastaların diz fleksiyon ve ekstansiyon zirve tork (ZT) değerleri ile uzun ve kısa taraf izokinetik kas kuvvet farkı kaydedildi (Tablo 1), (7).

\section{BULGULAR}

Çalışmada ekstremite boy farkı $9 \mathrm{~cm}$ (1. Olgu), $5 \mathrm{~cm}(2$. Olgu) ve $2 \mathrm{~cm}$ (3. Olgu) olan toplam üç sporcu alındı. Çalışmaya alınan olguların dominant taraflarının uzun taraf olduğu sözel olarak kaydedildi.

Bacak uzunluk farkı 5 ve $9 \mathrm{~cm}$ olan olgularda dominant bacağın $60^{\circ} \%$ s ve $180^{\circ} \%$ s hızlarda diz fleksör ve ekstansör kas kuvvetleri, non-dominant tarafa göre daha fazlaydı. Bacak uzunluk farkı $2 \mathrm{~cm}$ olan olguda non-dominant tarafin $60^{\circ} / \mathrm{s}$ ve $180^{\circ} / \mathrm{s}$ hizlarda ekstansör kuvveti ve $180^{\circ}$ /s hizda fleksör kuvveti fazlayken $60^{\circ} / \mathrm{s}$ hizda dominant tarafın fleksör kuvveti fazlaydı.

Diz fleksör/ekstansör kuvvet oranı bacak uzunluk farkı 5 ve $9 \mathrm{~cm}$ olan olgularda \%60'ın üzerinde iken, bu oran bacak uzunluk farkı $2 \mathrm{~cm}$ olan olguda \%60'ın altındaydı (Tablo 1 ).

\section{TARTIŞMA}

Üst veya alt ekstremitede eksiklikleri olan sporcuların Paralimpik sporlar listesinde yer alan pek çok sporu yapması mümkündür. Çalışmada üst ekstremite konjenital eksikliği ile birlikte alt ekstremitelerinde boy farkı da olan ve Paralimpik yüzme sporcusu olan üç olgudan, uzun taraf kas kuvvetinin boy farkı fazla olan iki olguda daha fazla olduğu ve bu farkın literatürde kabul edilen \%10-15'lik farktan (8) daha fazla olduğu belirlendi. Üçüncü olguda ise boyu uzun olan taraf ile kısa taraf arasında, uzun taraf aleyhinde kuvvet farkı olduğu, ancak bu farkın literatürde kabul edilen normal sinırlar (8) içerisinde oldugu belirlendi.

Literatür incelendiğinde değerlendirmeye alınan bu üç olguda olduğu gibi, hem konjenital üst ekstremite yokluğu hem de alt ekstremitelerde boy eşitsizliği olan bireylerde yapılmış herhangi bir çalışmaya rastlanmamıştı. Literatürdeki çalışmalar sağlıklı bireylerde yapılmış olup, bireyler arasında boy uzunluğu ile kas kuvveti arasında pozitif bir ilişski olduğu belirtilmektedir (5). Bu bilgiye paralel olarak sağlıklı bireylerde yapılan çalışmalarda kas hacmi arttıkça kas kuvvetinin de arttığı belirtilmektedir (4). Ancak kas kuvvetinin ayn zamanda genetik bazı faktörlerden de etkilendiği de bilinmektedir (9). Çalışmada aynı olgularda ekstremite eşitsizliği varlığı, boy uzunluğu ile kas kuvveti arasındaki ilişkinin genetik faktörlerden etkilenme olasılığını ortadan kaldırmaktadır. Bu durumda literatürde var olan boy uzunluğu arttıkça kas kuvvetinin artması durumunun; kas hacminin artmasiyla ilişkili olduğu yorumu yapılabilir. Bu bağlamda literatürde alt ekstremiteler arasında $0.5 \mathrm{~cm}$ 'lik kısalık farkının bile kas kuvvetini kısa olan ekstremite aleyhinde etkileyebileceği belirtilmektedir (10). Çalışmada açıklanan ilk iki olgu bu bağlamda literatürde var olan bu bilgi ile paralellik göstermektedir.

Çalışma sonucunda üçüncü olguda boyu uzun olan tarafın kas kuvvetinin daha az olduğu belirlendi. $\mathrm{Bu}$ olguda elde edilen bu sonuç; Bolz ve ark.nın yaptığı çalışmanın aksine, literatürde var olan 1-2 cm uzunluk farkının normal popülasyonda görülebileceğini ve bu durumun ileriki dönemlerde bel ağrısı dışında klinik bir sonuç yaratmayacağı bilgisini desteklemektedir $(11,12)$.

Çalışmada olguların dominant ve non-dominat kas kuvvet farkı incelendiğinde, özellikle $60^{\circ} / \mathrm{s}$ açısal hızda ve ekstansör kaslarda daha fazla olduğu belirlendi. Aynı zamanda olguların ekstansör/fleksör kuvvet oranı incelendiğinde, ilk iki olguda her iki açısal hızda ekstansörler aleyhinde olduğu belirlendi. Ancak kısa olan ekstremitelerde ekstansör kaslar aleyhinde olan bu oranın daha fazla olduğu belirlendi. Üçüncü olguda ise özellikle $60 \%$ a ç̧ısal hızda fleksörler aleyhinde kas kuvvet dengesizliği olduğu ve bu durumun kısa olan bacakta daha fazla olduğu belirlendi. Çalışmaya dahil edilen olguların aynı zamanda yüzme sporcusu olmaları, kişilerin 
ekstremitelerini kullanmıyor olabileceği ve kas kuvvet dengesizliğinin bu nedenle ortaya çıkmıș olabileceği şüphelerini ortadan kaldırmaktadır. Çalışmanın sonuçları ekstremite eşitsizliği olması durumunda kas kuvvetinin azaldığı ve agonistantagonist kas kuvvet dengesinin bozulduğunu ortaya koyabilir.

\section{SONUÇ}

Ekstremite kısalığı kas kuvvetini etkileyebilir. Diz eklemi kas kuvveti, alt ekstremite boy uzunluğu ile ilişkilidir. Alt ekstremite uzunluk farkı olan sporcularda, uzunluk farkı ile kas kuvveti arasındaki ilişkiyi inceleyen daha çok sayıda olgu içeren çalışmalara ihtiyaç vardır.

\section{KAYNAKLAR}

1. Tachdjian MO. Pediatric Orthopedics. Vol 2: Saunders; 1990.

2. Krebs DE, Edelstein JE, Thornby MA. Prosthetic management of children with limb deficiencies. Phys Ther. 1991;71(12):920-34.

3. Stoll C, Dott B, Roth MP, et al. Birth prevalence rates of skeletal dysplasias. Clin Genet. 1989;35(2):88-92.

4. Özkan A, Sarol H. Dağcılarda vücut kompozisyonu, bacak hacmi, bacak kütlesi, anaerobik performans ve bacak kuvveti arasındaki iliş̧i. Spormetre Beden Eğitimi ve Spor Bilimleri Dergisi.2008;7(4):175-81

5. Aydos L, Taş M, Akyüz M, et al. Genç elit güreşçilerde kuvvetle bazı antropometrik paremetrelerin ilișkisinin incelenmesi. J Phys Ed Sport Sci. 2009;11(4).

6. Kocahan T, Kaya E, Akınoğlu B, et al. The effects of isokinetic strength training on strength at different angular velocities: a pilot study. Turk J Sports Med. 2017;52(3):77-84.

7. Soylu C, Akınoğlu B, Yıldırım NU, et al. Examination of knee isokinetic strength and single balance of operated and non-operated side of patients with unilateral matrix induced autologous chondrocyte implantation (MACI) surgery: Pilot study. Turk J Sports Med. 2017; 52(3):93-102.

8. Lanshammar K, Ribom EL. Differences in muscle strength in dominant and non-dominant leg in females aged 2039 years-A population-based study. Phys Ther. 2011; 12(2):76-9.

9. Srinivasan RC, Lungren MP, Langenderfer JE, et al. Fiber type composition and maximum shortening velocity of muscles crossing the human shoulder. Clin Anat. 2007;20(2):144-9.

10. Bolz S, Davies GJ. Leg length differences and correlation with total leg strength. J Orthop Sport Phys. 1984;6(2): 123-9.

11. Anderpon M, Green WT, Messner MB. Growth and predictions of growth in the lower extremities. JBJS. 1963;45(1):1-14.

12. Aydın T. Osteopatik yaklaşım: alt ekstremite eşitsizliği ve bel ağrısı.Turk J Sports Med. 2015;50(4):163-72. 